\title{
The Approach of Gem and Jewelry's Corporate Core Values Development of Pranda Jewelry Group
}

\author{
N. Kecharananta and S. Sukcharoenphon
}

\begin{abstract}
The aims of the research were to study the core value development process and develop the approach of corporate core values for gem and jewelry business. This research used qualitative methodologies by in-depth interviewing with key informants; Pranda worker, specialists and experts on gem and jewelry business, including stakeholders from suppliers, shareholders and communities. The research result found that The approach of corporate core values for gem and jewelry business consists of 7 factors as follows: 1. The concept of corporate core values should focus on product quality with human-centered consideration. 2. Top executive defines development goal on core values while consultant surveys and finds out shared characteristics of employee. 3. Executives value and give importance to all stakeholders including customers, suppliers, shareholders and employees. 4. Core values development should support the change rather than hold on shared principles in organization. 5. Core values development starts from vision, then aligns core values in line with the vision and communicates vision and core values throughout the organization. 6. Core values should have committee or team members from various departments and 7. Core values are integrated with human resource management on employee development and retention. With the execution of this approach, the Thai gem and jewelry business will have competitive advantage and sustainable growth.
\end{abstract}

Index Terms-Core values development, gem and jewelry business.

\section{INTRODUCTION}

Gem and jewelry industry needs a great deal of expertise for manufacturing, so the main objective of the organization is improving skilled labors and products. It is challenging for the industry to make their personnel have the same objective and behave in the same way. Since majority of personnel is craftsmen, they need plans for communication, acknowledgement, mutual understanding creation, positive attitude towards products, trademark, and organization. These things can happen by collaboration from every personnel and committing to the objective of the organization together. Thus organizational core value creation must be set as the objective of working together, in order to be used as a guideline for personnel to see value, realize, and understand.

Organizational core value has been used widely in organizations around the world. Generally, most organizations have a clear organizational value. Many organizations have asked questions about quality of management system and capability for promoting value that

Manuscript received January 20, 2015; revised April 12, 2015

The authors were with Suan Dusit Rajabhat University, BKK 10300 Thailand (e-mail: natsdu@hotmail.com, kor5858@yahoo.com). benefits organization; and have tried to apply organizational value with real practice so as to make advantage for competition [1]. Many organizations in Thailand have placed importance on organizational value and culture [2], so they made core value and educated their personnel. If their personnel follow organizational value, it would lead to management system which has excellence as a goal and achieve business goal.

Pranda Jewelry Public Company Limited is a manufacturer, distributor, and retailor of genuine jewelry, currently one of Thailand's major jewelry exporters. It has placed importance on creating organizational core value with a guideline of social responsibility. It is the core for pushing the organization towards the goal by emphasizing on personnel to use their potential efficiently as the main capacity of the organization [3]. Furthermore, it has strategy for business growth emphasizing on brand development that is based on its core value, in order to make every personnel be a part of the organization, understand themselves and organizational core value, and move towards the goal and success of the organization together. Therefore, the researcher is interested in studying the issues related to the core value of Pranda Jewelry, in order to propose a means for improving core value of gem and jewelry industry.

\section{Methodology}

\section{A. Quantitative Methods}

Quantitative Research is done by collecting data from employees of Pranda Jewelry Public Company Limited with questionnaire. To study opinions towards organizational core value and core value application of personnel in gem and jewelry industry.

\section{B. Qualitative Methods}

Qualitative part is done by in-depth interviewing main data providers; employees, experts or executives in the jewelry, and stakeholders. And focus groups were collected by data providers; executive Pranda Jewelry, academics, and administrator of Gem and Jewelry Institute. To study a means for developing organizational core value for enhancing competence in gem and jewelry industry.

\section{RESULTS AND DISCUSSION}

\section{A. Quantitative Research Methodology}

There were 352 personnel at Pranda Jewelry Public Company Limited who answered the questionnaire. Most of them are 18-29 years old female who earned Bachelor's 
degree or lower with the same number. They have worked at the company or have experience in gem and jewelry industry less than 10 years. They have opinions towards organizational core value and use the organizational core value with their work at the highest level. Moreover, it was found that they suggested that Pranda Jewelry should have organizational core value that promotes teamwork, continuous improvement, stakeholder focus, appropriate benefits and pay, manufacturing and technology improvement, personnel improvement, and education for personnel.

\section{B. Qualitative Research Methodology}

Organizational core value creation process of gem and jewelry industry.

1) The concept of organizational core value of gem and jewelry industry must emphasize on quality of product, design that corresponds to market's needs, and personnel as the center. Quality of product depends on material, equipment, craftsmen, which are important factors for manufacturing jewelry. So they need to understand, access, encouraged, and protect personnel. Organizational core value must reflect capacity of personnel in the organization, so as to be used as a guideline for working continuously. Administrators of the organization must have a plan for campaigning to personnel so as to make them know and use it.

2) Organizational value creation process should start with brainstorming from the board of administrators, in order to create organizational value by reviewing structure of vision, mission, and core value, which correspond to core value design. Furthermore, chief executives must set the goal for creating value that medium level executives and human resource department would be connectors for organizational value searching process with lower level personnel. The obtained value should connect to capacity and has been tested for real practice. It should have 3-6 items so as to reflect good things and can be used as a capacity model for selecting personnel, improving personnel, and evaluating personnel. Organizational value might be activity that became strong organizational culture that makes everyone commits to the organization.

3) The first 5 factors that support organizational core value creation or improvement of gem and jewelry industry includes personnel accept and participate, administrators follow value as a role model, administrators place importance and support, give budget to support core value, and administrators have vision.

4) Organizational core value application needs participation of personnel by organizing activities until it becomes organizational culture. As a result, personnel would commit to the organization. Moreover, the organization would be able to assess their capacity by using core value to select personnel, evaluate personnel, and improve personnel.

According to qualitative and quantitative research methodology, means for improving organizational core value of gem and jewelry industry were synthesized in 7 aspects as follows:

1) The concept of organizational core value of gem and jewelry industry must emphasize on quality of product by letting personnel to be the center and improve personnel to work with quality, honesty, and good quality of living.

2) Chief executives are the ones who set the goal of organizational core value while exploring and searching for co-characteristics of personnel inside the organization must be done by consulting firm, since chief executives tend to set goal of organization that corresponds to their own value instead of personnel's.

3) Administrators pay attention to every group that involves with the organization, including customers, business partners, shareholders, and personnel; and place importance to every stakeholders both inside and outside the organization.

4) Organizational core value creation must support changes rather than using value as merely principle inside organization such as value of working as a team for pushing changes because leader or chief executive alone might not strong enough to make any change.

5) Organizational core value creation begins with vision improvement and then plan the structure of organizational core value that corresponds to the vision. After that, spread the vision and value throughout the organization, in order to make personnel realize and apply the core value with their practice that would lead to achieving the goal of the organization.

6) Organizational core value should have working group or team with representatives from different departments for coordinating, meeting, and following up, because organizational core value must be supported from every level in the organization.

7) Integrate organizational core value with human resource management which is human resource development such as personnel selection, personnel improvement, personnel evaluation, and concept of personnel preservation by giving rewards and promotion, for instance.

\section{CONCLUSION}

\section{A. Organizational Core Value and Organizational Core Value Application by Personnel of Pranda Jewelry}

Personnel of Pranda Jewelry have opinions towards organizational core value and have behaviors of applying the organizational core value with their practice at the highest level. It is corresponds to a means for creating organizational culture of TOT Public Company Limited. It was found that perception for organizational culture of the personnel is at high level. Furthermore, the study on core value application found that an efficient means for core value application needs a process which is a part of business plan. Symposium and forum are necessary elements for studying thoroughly and training process that all personnel should participate.

\section{B. Organizational Core Value Creation Process of Gem and Jewelry Industry}

1) Concept and form of organizational core value of gem and jewelry industry

Organizational core value must emphasize on quality of product which have design that corresponds to market's needs 
and emphasize on viewing personnel as the center. Quality of product depends on material, equipment, and craftsmen, which are important factors for manufacturing jewelry. So they need to understand, access, encouraged, and protect personnel. The organizational core value must reflect capacity of personnel in the organization, so as to be used as a guideline for working continuously. Administrators of the organization must have a plan for campaigning to personnel, so as to make them know and use it. It corresponds to the notion of Sethkriangkrai (2010) who concluded that products in gem and jewelry industry have delicacy that suitable for Thai people, so the products have high quality as foreign markets need [4]. Moreover, workers in this industry are trained to be skilled labors that correspond to suggestion of the Thai Chamber of Commerce (2009) that searching for skilled labors to replace the current ones is difficult [5]. Thus the Thai Chamber of Commerce has recommended a strategy for improving workers' skills - producing skillful workers and creating pride for craftsmen.

\section{2) Organizational core value creation process}

Organizational value creation process should start with brainstorming from the board of administrators, in order to create organizational value by reviewing structure of vision, mission, and core value, which correspond to core value design. It corresponds to 5 procedures of modern organizational culture creation defined by Chuito (2004), including adding culture to vision, mission, and value of organization; workshop; education and training; work assessment; and personnel rewarding system [6]. Furthermore, chief executives must set the goal for creating value that medium level executives and human resource department would be connectors for organizational value searching process with lower level personnel. The obtained value should connect to capacity and has been tested for real practice. It should have 3-6 items so as to reflect good things and can be used as a capacity model for selecting personnel, improving personnel, and evaluating personnel. Organizational value might be activity that became strong organizational culture that makes everyone commits to the organization. It corresponds to Collins and Porras's (2002) study [7]. They states that company of vision should have 3-6 items of core value because achievement mainly depends on belief. If organization creates value more than 6 items, the organization would not be able to see the real core value.

\section{Factors that Support Organizational Core Value Creation or Improvement of Gem and Jewelry Industry}

\section{1) Personnel accept and participate}

Letting members in the organization or personnel and administrators in the organization participate in activities relating core value in the organization, for example, letting personnel decide how to make the organization achieve the goal. Furthermore, core value application: necessity of modern era found that an efficient means for core value application needs a process which is a part of business plan. Symposium and forum are necessary elements for studying thoroughly and training process that all personnel should participate. In the process, administrators must be enthusiastic to make everyone sees the importance. Planning and doing are not enough, because core value application is a part of leader's responsibility.

\section{2) Administrators follow value as a role model}

Wongmontha (2007) states that leaders should be a role model for personnel, because they always copy their leaders' behaviors [8]. So leaders are the ones who set the working standard for personnel in the organization. Therefore, it can be said that "Personnel in organization are what leader is". This statement is equivalent a Thai proverb that "No shaking head, no wagging tail." Leaders must set a goal for organizational culture creation by using their own behaviors as a role model for growing culture. Moreover, Rodsutthi (2008) states that administrators are considered as a model for organization automatically [9]. If they can be a good role model for members in the organization, communication would be more efficient. Also, Saritwanit (2009) suggests that the way how chief executives behave from generation to generation, which is being a role model continuously and constantly, would be a value and ways of practice created by the founder [10].

\section{3) Administrators place importance and support}

Osborne (1991) studied organizational core value saying: organizational direction of public companies, like Johnson \& Johnson, General Electric, and Progressive Corporation [11]. It was found that important managers should have a role with company owner in the process of organizational core value saying development and the process of belief achievement that encourage and control the organization.

\section{4) Giving budget to support core value}

Barrile (1995) studied new organizational value development of Ansett Australia [12]. It was reported that Ansett had to review organizational culture program, in order to be success in business after regulations of Australian aviation industry were canceled. The chief executives had commitment to budget for supporting activities and the content of organizational culture program.

\section{5) Administrators have vision}

Kotler, Kantachaya, and Setiawan (2011) state that while "mission" deep rooted to the past since company establishment, "vision" is a picture of the future that the company expects and wishes to be. In order to set a vision, the company needs to draw a picture of the future in mind by focusing on the mission [13]. Vision is like a compass for directing the company to the future. Moreover, Wongmontha (2007) states that a good leader must have a far vision and knows what to do with the organization in long-term [8].

\section{Organizational Core Value Application}

Organizational core value application needs personnel's participation by organizing activities, and then it would be organizational culture that personnel commit to the organization. Furthermore, the organization can assess capacity from the core value, in order to select personnel, assess personnel, and improve personnel. Dahlgaard, Dahlgaard-Park, and Edgeman (1998) found that applying core value through reward and recognition followed by working assessment would reflect leadership systematically [14]. In addition, 360 degree assessment of Alyn (2001) is an 
assessment that obtains data from subordinates, managers, coworkers, or people around us [15]. It is an assessment process that creates responsibility to organizational core value. The assessment is separated into main category assessment - core value - and minor category assessment behaviors that reflect core value. It assesses how personnel live with organizational core value and personal value.

\section{E. Means for Organizational Core Value Improvement of Gem and Jewelry Industry}

There are 7 means for organizational core value improvement of gem and jewelry industry as follows:

1) The concept of organizational core value improvement of gem and jewelry industry needs to focus on quality of product by viewing personnel as the center. In other words, it is a means for improving quality of personnel so as to have honesty and good quality of living that corresponds to a study done by Setkriangkrai (2010) [4]. The study found products of gem and jewelry industry have delicacy that suitable for Thai people, so the products have high quality. At present, Thai craftsmen in gem and jewelry field are accepted internationally.

2) Chief executives are the ones who set the goal of organization value while exploring and searching for co-characteristics of personnel inside the organization must be done by consulting firm, since chief executives tend to set goal of organization that corresponds to their own value instead of personnel's. It corresponds to a study done by Kersten (2005) who found that organizational core value development should be done by consulting firm because chief executives tend to set core value by considering benefits and value of shareholders [16].

3) Administrators pay attention to every group that involves with the organization, including customers, business partners, shareholders, and personnel; and place importance to every stakeholders both inside and outside the organization. It corresponds to studies of Kraatz, Ventresca, and Deng (2010) and Suddaby, Elsbach, Greenwood, Meyer, and Zilber (2010) who found that organizational value is influenced by stakeholders and personnel inside organization [17]-[18]. Moreover, value is created by chief executives, personnel, environment, and stakeholders [19]. Furthermore, there are 3 steps for organizational value setting. Administrators are not only the ones who set organizational value, but should also let shareholders, customers, business partners, community, and society, participate in setting organizational value as well, because these people are the ones who receive benefits from operation of the organization.

4) Organizational core value creation must support changes rather than using value as merely principle inside organization. Gibson (2008) found that it is possible that culture is necessary for helping changes, not only for controlling [20]. He states that companies which have culture and business with high competition would have more market share. Thus if it is possible to predict a decade of change quickly, organizational culture creation is needed, because it would help companies to adapt with changes.
5) Organizational core value creation begins with vision improvement and then plan the structure of organizational core value that corresponds to the vision. After that, spread the vision and value throughout the organization, in order to make personnel realize and apply the core value with their practice that would lead to achieving the goal of the organization. World class companies of vision focus on a process that makes all personnel approve. The vision composed of 3 elements 1 . reasons that organization exists for not only to make profit which is usually called mission or objective, 2 . permanent core value, and 3. determination for achieving the goal.

6) Organizational core value should have working group or team with representatives from different departments for coordinating, meeting, and following up, because organizational core value must be supported from every level in the organization. Osborne (1991) studied organizational core value saying: organizational direction of public companies, like Johnson \& Johnson, General Electric, and Progressive Corporation [11]. It was found that important managers from different departments should have a role with company owner in the process of organizational core value saying development and the process of belief achievement that encourage and control the organization.

7) Integrate organizational core value with human resource management which is human resource development. Personnel which have been recruited by the organization would advance through the process of personnel selection, in order to make them have ability and attitude that correspond to organizational culture. Moreover, giving reward is a tool for motivating personnel to stay and pass on core value [10]. It corresponds to Hassan (2007) who found that human resource improvement process, like assessment and promotion, has positive relationship with organizational core value that focus on collaboration and quality [21].

\section{REFERENCES}

[1] R. Van Lee, L. Fabish, and N. N. McGraw, "The value of corporate values," Strategy and Business, vol. 39, pp. 1-14, 2005.

[2] R. Asisonthisakul. (2009). Work culture (2). Monthly Newsletter National Productivity Institute. [Online]. 10(110). Available: http://www2.ftpi.or.th/th/knwinf_pcornerdetailDotnet.php?pdtlid=75 5

[3] P. Tiasuwan. (2013). Message from the president. [Online]. Available: http://www. pranda. com/www /message_chairman.aspx

[4] A. Sethkriangkrai. (2010). Technology to produce jewelery industry and other important? [Online]. Available: http://www.oie.go.th

[5] Thai Chamber of Commerce. (2009). jewelry business development strategy. [Online]. Available: http://www.thaichamber.org/scripts/stratigic.asp $\mathrm{Tag}=7 \&$ nShowMag $=1 \&$ nPAGEID $=88$

[6] S. Chuito, Modern Organization, 2nd ed. Bangkok: Sukhothaithammathirat University, 2004.

[7] J. C. Collins and J. J. Porras, Built to Last Successful Habits of Visionary Companies, Bangkok: Managermedia Group, 2002.

[8] S. Wongmontha, Active Leader 360, Bangkok: Than Printing, 2007.

[9] M. J. Rordsutthi, The Holistic People Management, Bangkok: Matichon, 2008.

[10] S. Saritwanit, Modern Organizational Behavior: Concepts and Theories, Bangkok: SE-EDUCATION, 2009.

[11] R. L. Osborne, "Core value statements: The corporate compass," Business Horizons, vol. 34, no. 5, pp. 28-34, 1991. 
[12] S. Barrile, "Developing a new corporate culture," Businessdate, vol. 3 , no. 2, pp. 1-4, May 1995.

[13] P. Kotle, H. Kartajaya, and I. Setiawan, Marketing 3.0, Samutprakarn: Nationbook, 2011.

[14] J. J. Dahlgaard, S. M. Dahlgaard-Park, and R. L. Edgeman, "Core value deployment: The need for a new renaissance," Total Quality Management, vol. 9 no. 4/5, pp. S45-S50, July 1998.

[15] K. Alyn, "Using your core values to evaluate behavior: Design a 360-degree evaluation to create a solid foundation," Firehouse, p. 40, October 2011.

[16] E. L. Kersten, “Core values, devalued," Workforce Management, vol. 84, no. 6, pp. 10-12, June 2005.

[17] M. S. Kraatz, M. J. Ventresca, and L. Deng, "Precarious values and mundane innovations: Enrollment management in American liberal arts colleges," Academy of Management Journal, vol. 53, pp. 1521-1545, 2010.

[18] R. Suddaby, K. D. Elsbach, R. Greenwood, J. W. Meyer, and T. B. Zilber, "Organizations and their institutional environments: Bringing meaning, values, and culture back in," Academy of Management Journal, vol. 53, pp. 1234-1240, 2010.

[19] J. Gehman, L. K. Treviño, and R. Garud, "Values work: A process study of the emergence and performance of organizational values practices," Academy of Management Journal, vol. 56, no. 1, pp. 84-112, February 2013.

[20] R. Gibson, Rethinking the Future, Bangkok: SE-EDUCATION, 2008.

[21] A. Hassan, "Human resource development and organizational values," Journal of European Industrial Training, vol. 31, no. 6, pp. 435-448, 2007.

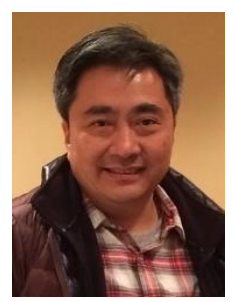

Nattaphan Kecharananta was born in Bangkok, Thailand. He had such diverse background from engineering, economics, business management and IT. Dr Nattaphan obtained his Ph.D. degree from Alliant International University, USA, 1995 in the field of leadership and human behaviors.

He currently works as a director of doctoral program in business management and teaches at the Graduate School, Suan Dusit Rajabhat University, Bangkok Thailand. He also supervises students dissertation in doctoral level in various universities but mainly Suan Dusit Rajabhat University. Moreover, he was invited as a adjunct professor to teach many universities such as: Chulalongkorn University; Thammasat University; King Mongkut's University of Technology Thonburi; King Mongkut's University of Technology North Bangkok; Maejo University; Ramkhamhaeng University and Rajamangala University of Technology Lanna. His research interests were on business, management, industrial economics and human resources.

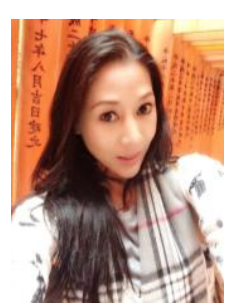

Supasagee Sukcharoenphon was born in Samuthprakarn, Thailand. She is a doctorate student majoring in business management at Suan Dusit Rajabhat University, Bangkok Thailand. Supasagee received her bachelor and master degrees from the USA.

Currently, She is a chief executive of Kindergarten, a committee member and an administrative assistant of Sukcharoenphon School. Moreover, she also holds a position as a committee member of Supakin CO, LTD. 